\title{
Use of Photovoltaics in Microgrid as Energy Source and Control Method using MATLAB/Simulink
}

\author{
Sumaiya Rahman, Hasimah Abdul Rahman \\ Centre of Electrical Energy Systems (CEES), Institute of Future Energy, Fakulti Kejuruteraan Elektrik, Universiti \\ Teknologi Malaysia (UTM), 81310 Johor Bahru, Johor, Malaysia
}

\begin{tabular}{l} 
Article Info \\
\hline Article history: \\
Received Oct 13, 2015 \\
Revised Dec 9, 2015 \\
Accepted Jan 3, 2016 \\
\hline Keyword: \\
Controller \\
Distributed energy resources \\
Microgrid \\
Photovoltaic
\end{tabular}

Photovoltaic

\begin{abstract}
Microgrid in power system has drawn wide attention due to its significant benefits in terms of sustainable energy system in recent years. This approach is the most economical alternative to conventional energy system which uses Renewable Energy (RE) resources.RE sources ensurepollution free and clean environment by emitting zero $\mathrm{CO}_{2}$. This paper proposes a design of a microgrid system using solar photovoltaics (PV) as the Distributed Energy Resources (DERs) and a controlling method for managing the components of microgrid by using MATLAB/Simulink. The results show that microgrid system is promisingas alternative to replace the fossil fuel based energy system. Integration of an effective controller can help to manage the loads and resources, resulting in more stable and reliable.
\end{abstract}

Copyright (c) 2016 Institute of Advanced Engineering and Science. All rights reserved.

\section{Corresponding Author:}

Hasimah Abdul Rahman

Block P19a - 01-11-00, Pusat Sistem Tenaga Elektrik (CEES),

Fakulti Kejuruteraan Elektrik, Universiti Teknologi Malaysia (UTM),

81310 Johor Bahru, Johor, Malaysia.

Phone: +607-555 7002/7006

Fax: +607-555 7005

Email: hashimahar@utm.my

\section{INTRODUCTION}

Electricity demand is increasing rapidly with the increasing population growth rate. The development in technologies worldwide is also another key factor for high increase in electricity demand. For these reasons, fossil fuels such as oil, coal, gas are depleting acutely. Meanwhile, use of carbon based fuels causes harmful effect to the environment by releasing tonnes of toxic Green House Gases consisting of Carbon dioxide, Methane, Nitrous oxide, Ozone and Chlorofluro carbon every year [1], [2]. These have made it extremely necessary to seek for favourable alternative forthese fossil fuels, which are sufficient to fulfill the demands and do not damage the environment [3]. Microgrid (MG) system is potential as alternative as it usesrenewable energy, reduces carbon emission andbeing economically friendly [4].

However, it is a great challenge to control Microgrids to maintain balance in the whole system to work as a coordinated unit. This is considered as a crucial condition in the system [5]. First of all, this system basically uses Renewable Energy as energy source. Therefore, variation in generation of RE sources takes place due to the change in weather condition which leads to poor power quality [6], [7]. When the system is in grid-connected mode, some disturbances in utility may cause severe damage in MG system requiring a controller for disconnection from. As a consequence of disconnection, voltage and frequency imbalance may occur in MG and in this case for maintaining harmony microsource controllers are needed [8]. Moreover, in stand-alone condition, controlling DERs are essential to establish voltage and frequency stability within the microgrid for the balance in different loads and storage modules as well [9]. In islanded and low generation condition, it is necessary to feed the most critical loads and shade the non-critical loads. Hence, an intelligent 
controller is needed for this task. Thus, control requirements and techniques are significantly different compared to the conventional power system. The aim of this project is to design and propose a high performance Microgrid system by integrating DERs and an automated controller.

\subsection{Architecture Ofmicro-Grid (MG) System}

Microgrid is a small scale power system in which Renewable Energy (RE) sources such as Solar Photovoltaics, Wind Turbines, Fuel cells, Biomass energy and others [or known as Distributed Energy resources (DERs)] are used to serve a small community [10-12]. MG can be operated using non-RE sources (i.e. Fossil Fuel based generators) as well. However, Energy Management System in microgrid is different than the traditional power system as it uses different loads, a range of Distributed Generators (DGs), Distributed Energy Storages (DESs) and converters. [13].

Basically, in MG systems, local users have more control on power sources and uses. Also, in these systems, some low level power-producing sources and elements are jointly used to generate, transmit and distribute electricity to a small community, allowing remarkably less transportation cost. Those components usually remain connected to computer systems for monitoring, controlling and balancing energy demands, supply and storages [14]. These components can provide feedback and also can take actions according to the variation in energy demands. To increase flexibility, MG system should have self-healing capability. Figure 1 shows a scenario of typical MG, in which, main components are solar PV, wind turbine, inverters, controller, critical loads, non-critical loads and battery.

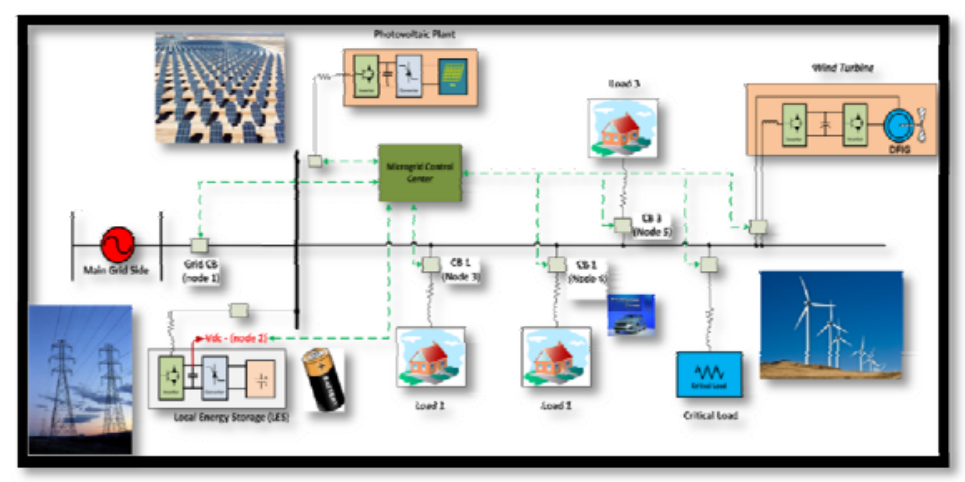

Figure 1. Architecture of Microgrid with multiple DERs, batteries, critical load, noncritical load, PCC and Utility grid [15]

Power system of a microgrid also consists of energy storage module, power forecasting module, power converters, controller unitsand communication network [16-20]. In this study, solar photovoltaics, wind energy and fuel cell have beenselected as energy source for the microgrid. However, this paper will only discuss on the use of PV as the MG and the controlling method to manage the components in the MG system-

\subsection{Microgrid Controling System}

Considering the integration of multiple DERs, incorporation with different loads and main utility grid through inverters in MG [21], a management system is certainly needed for maintaining a harmony in the system. In microgrid system operation, monitoring, controlling and optimization are some of the technical sectors which need to be fulfilled to ensure reliable and more effective system [22]. A controller for the system is needed for balancing the energy, as well as the loads within a very short time period and for cost effective operation [23]. The controller of Microgrid uses local information to control the components and responds within milliseconds [24]. The function of a controller in MG consists of improvements to MG efficiency, power flow control, resynchronization between the MG and the main grid, adjustments of voltage and frequency in both modes [25, 26].

MG controls can be classified as below:

i. Local Control: Basic category of MG control is by controlling the operating points of the microsources and power-electronic admix [27]. This control is low cost due to no requirement of communication network, and normallyemployed in islanded mode by measuring local voltage current data [28]. 
Connection and disconnection of MG sources and components from distribution network are necessary [29].

ii. Centralized Control: The operating hypothesis is similar as Local control but is smarter and intelligent control technique [20]. Suitable for loads and microsources with common goal and small scale MG [23, 30]. It can be assumed as hierarchical control with Local control, Microgrid central controller (MGCC) and Distribution Management System (DMS) [30], [31].

iii. Decentralized Control: To maximize self-government of the microsources and loads is the target of decentralized control [27]. Helps to optimize production and exportation of energy [27].

Studies conducted by [30] showed the complication in controlling various components of MG due to their different characteristics for example disconnection between the main grid and MG or between MG and non-critical loads that will lead to huge voltage and frequency imbalance [32]. As a result, controller is essential for proper operation of MG. This paper presents a central controller system for microgrid which is adopted and improved from [33].

\section{METHODS}

This paper presented a standalone MG system where PV is chosen as the energy source. The PV generating system and the controller had been designed using MATLAB/Simulink, whose configuration is as in Figure 2. The left part of Figure 2 shows a general diagram of the central controller that was used mainly to control the circuit breakers of non-critical loads and the main grid which is the. The right part shows the designed microgrid system model and simulation model used in this study. This controller has two functionalities, such as, (i) Measuring and (ii) Comparing. Usually for a single DER unit (PV only) it requires only a simple controller.

The simulations were performed to validate the effectiveness of the designed controller in [33]. In the simulation, islanded mode operation was considered in order to understand the role of the controller. Meanwhile, the microgrid was designed using three DERs such as Solar PV, Wind Turbine and Fuel Cell. However, only PV was used in this simulation.

There are three operating modes in microgrid, which are [17] [24] [34]:

i. $\quad$ Grid connected mode (Normal mode)

ii. Islanded mode or autonomous mode (When faults occur at Main grid)

iii. Transition between grids connected and islanded mode.

The loads were then categorized into two sections in accordance with the preferences. Some critical (i.e. hospital) and non-critical loads (electrical vehicle, some residential loads) were selected, and the first type of loads needed continuous energy supply. On the other hand, the non-critical loads which were connected to the microgrid through circuit breakers (CB) could be ignored during the peak time. This situation would be applied (non-critical loads disconnect) when the generated power by solar PV was less than the demand in the microgrid. The controller functioned to control the AC voltage that had the same voltage level at Point of Common Coupling (PCC). The loads were fully supplied by renewable Solar PV energy source.

Figure 2 also indicates that it is a three-phase AC MG system where three voltage measurement blocks were used to measure three phase voltage signals. Alsothree RMS blocks were connected respectively with each voltage measurement block to generate RMS value. As for the control system, a threshold level was set in the constant value block, which was the RMS value of three phase voltage (at PCC). At this stage, three comparators were connected to the three RMS blocks, respectively. The comparators of the controller compared the voltage value with the threshold level and then intelligent decisions were taken by the controller's logic gates accordingly. Finally, these gates were directly connected to the circuit breakers of non-critical loads. The critical loads should have continuous power supply. Hence, those loads are needed to be connected consistently with the system. Therefore, CBs were not connected to critical loads. 


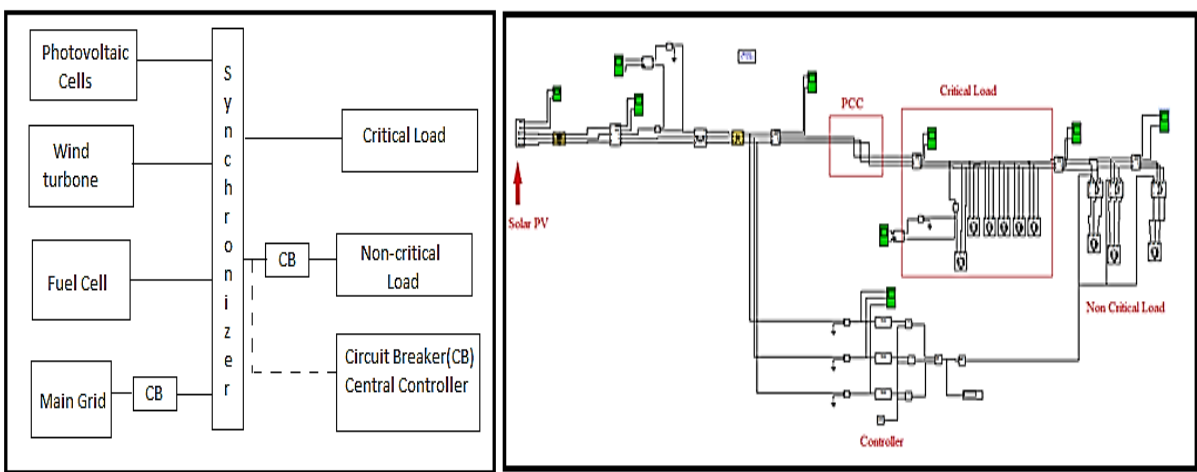

Figure 2. Left: Block diagram of a microgrid with central controller [33]; Right: Designed Microgrid system in Simulink using PV source with controller

Figure 3 shows the proposed Microgrid system with three distributed energy sources with some critical loads and non-critical loads. For simulation, the MG was connected to the main grid through a point of common coupling, while at the main grid side, a controller was used to control the loads of MG. The whole system was designed using MATLAB/Simulink and the controller was slightly modified according to the parameters of PV, since they [33] used Wind Turbines and synchronous generator.

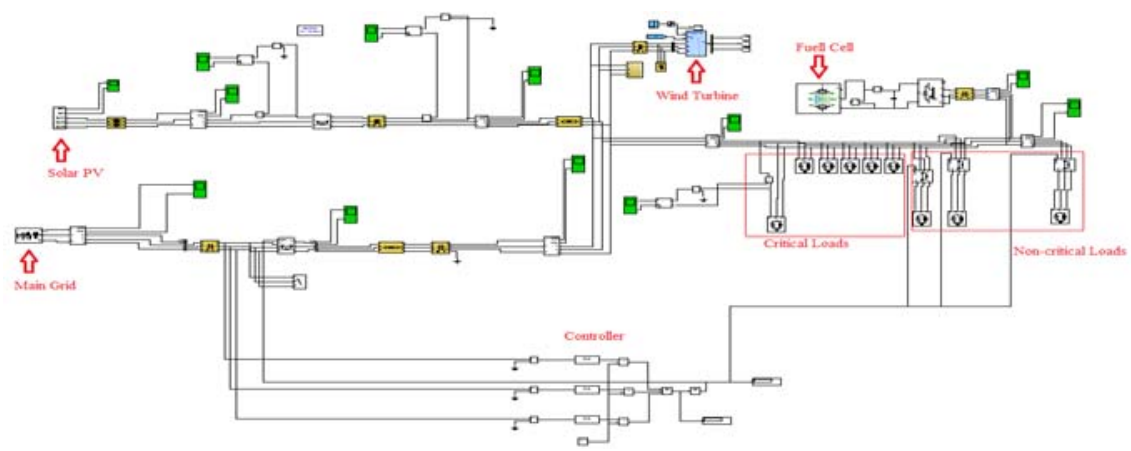

Figure 3. Proposed Microgrid system with three DERs: Solar Photovoltaics, Wind Turbines and Fuel Cell

\section{RESULTS AND DISCUSSION}

\subsection{System Components}

Table 1 indicates the specifications of the PV module which were used in the simulation model of MATLAB/Simulink in this study.

Table 1. PV data taken from the KC200GT solar array datasheet

\begin{tabular}{cc}
\hline Name & Values \\
\hline Short-circuit current & Isc $=8.21 \mathrm{~A}$ \\
Open-circuit voltage & Voc $=32.9 \mathrm{~V}$ \\
Array current at maximum power point & $\mathrm{Impp}=7.61 \mathrm{~A}$ \\
Array voltage at maximum power point & $\mathrm{Vmpp}=26.3 \mathrm{~V}$ \\
Maximum Power & $\mathrm{Pmax}=200 \mathrm{~W}$ \\
Irradiance & $1000 \mathrm{~W} / \mathrm{m}^{2}$ \\
Module Temperature & $25^{\circ} \mathrm{C}$ \\
Number of Series Modules & 50 \\
Number of Parallel Modules & 500 \\
\hline
\end{tabular}

Table 2 lists the same load parameters used in simulation as in [33]. Among these 8 loads, 5 were set as critical loads and 3 loads were set as non-critical. 
Table 2. Details of Load parameter

\begin{tabular}{cc}
\hline Name of the Components & Detailes \\
\hline No. of identical loads & 8 \\
Line to line voltage & $415 \mathrm{~V}$ \\
Frequency & $50 \mathrm{~Hz}$ \\
Active power & $500 \mathrm{~kW}$ \\
Inductive power & $242161 \mathrm{VAr}$ \\
Power factor & 0.9 \\
\hline
\end{tabular}

\subsection{Simulation Results and Discussion}

In the simulation, during the period when generated output power by PV became more than load demand, the line voltage at the PV side and load side were set at 415V [11]. Figure 4 shows the critical and non-critical load conditions when the total power produced by the MG (5MW) became higher than the total load demand (4MW). The figure also shows the voltage and current levels at PCC. In this case, the line voltage had increased approximately up to 550V. Figure 5 to Figure 8 show the critical and non-critical load conditions when the total power produced by the MG (3MW) was lesser than the total load demand (4MW), with the voltage and current levels at PCC.

In the case of without controller, the voltage level at PCC, critical and non-critical load side had been reduced by $25 \%$ (from the set line voltage value, which was $415 \mathrm{~V}$ ). This was due to less output power than the load demands (refer Figures 5 and 6).
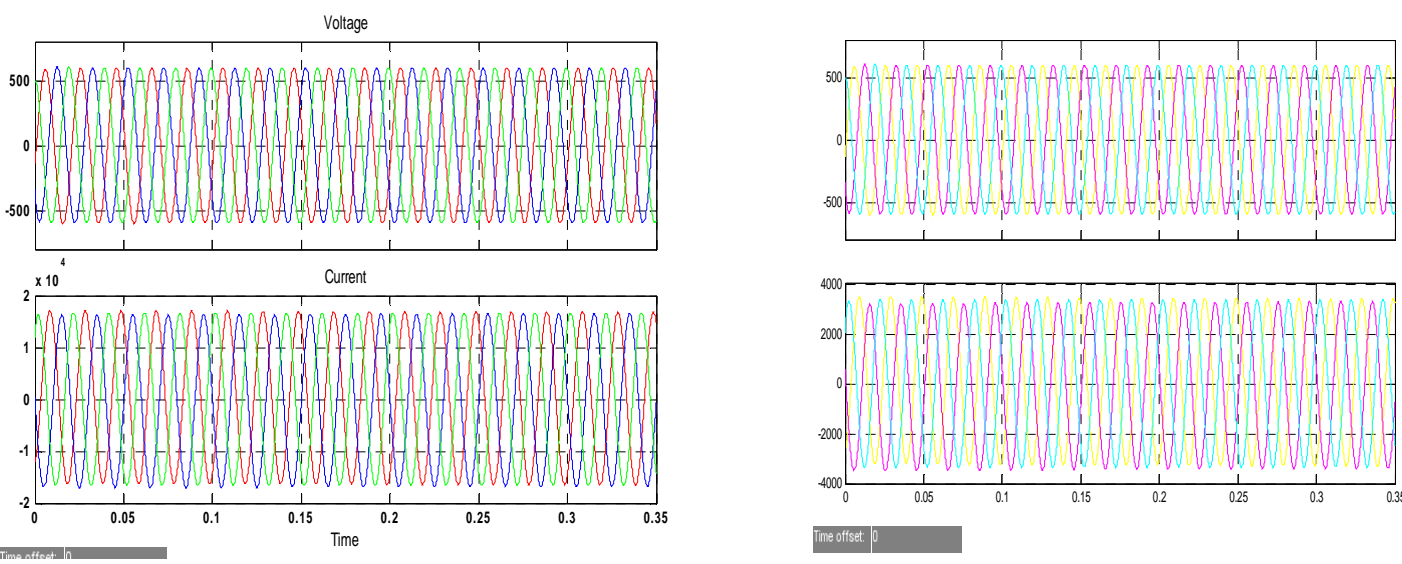

Figure 4. Voltage (top) and current (bottom) signals at PCC (Left) critical load side (Line voltage 550V) (Right)
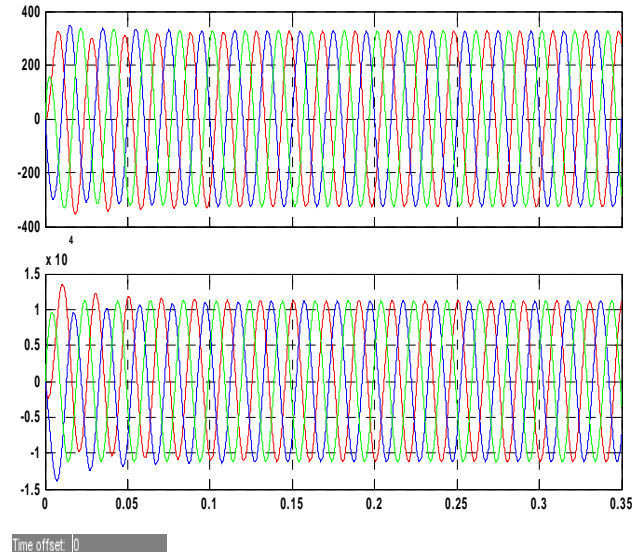
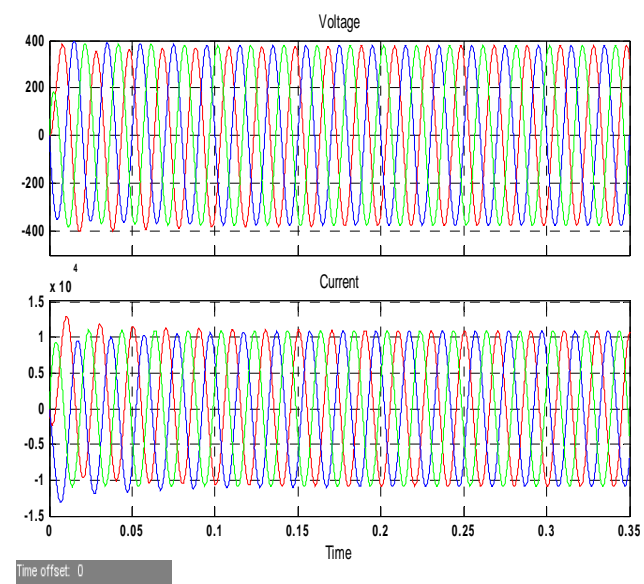

Figure 5. Voltage (top) and current (bottom) signals at PCC (the left side shows drop of Line voltage below $400 \mathrm{~V}$, while the right side shows increase of Line voltage to $400 \mathrm{~V}$ after using the controller) 

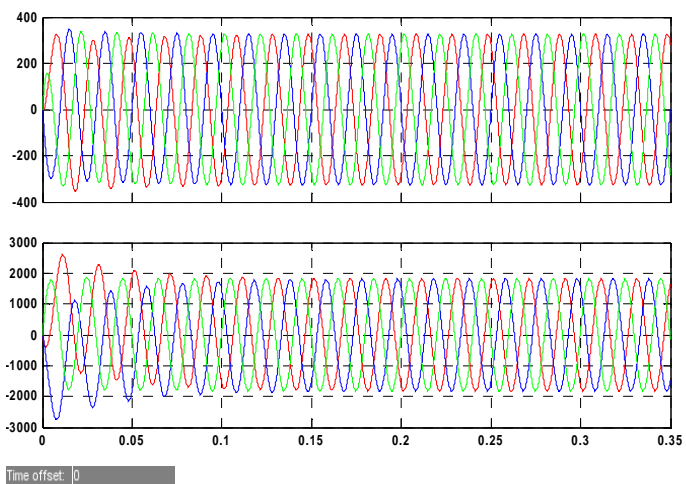
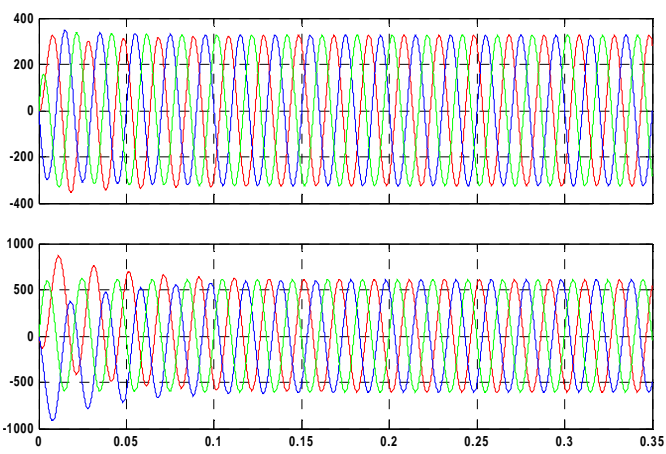

Figure 6. Voltage (top) and current (bottom) signals at critical load side (left) and at non-critical load side (right) (Line voltage dropped below $400 \mathrm{~V}$ and became became estimatedly 320V)

For the case when the controller is in operation, when the power level is less than demand, the controller will instruct the circuit breakers of non-critical loads to be disconnected. This will maintain the voltage level that supplies the critical loads.

The controller functioned to compare the RMS value of voltage signals, as in Figure 7 at PV side. Figure 8 indicates the current flow for the non-critical load at zero, meaning that it was disconnected. In addition, when the RMS value declined to below $300 \mathrm{~V}$, the controller would cut off the non-critical loads, and all the power would be delivered to critical load, hence the voltage level increased again. This means the controller could sense that the RMS value of voltage was below threshold level (the set point was 300V).

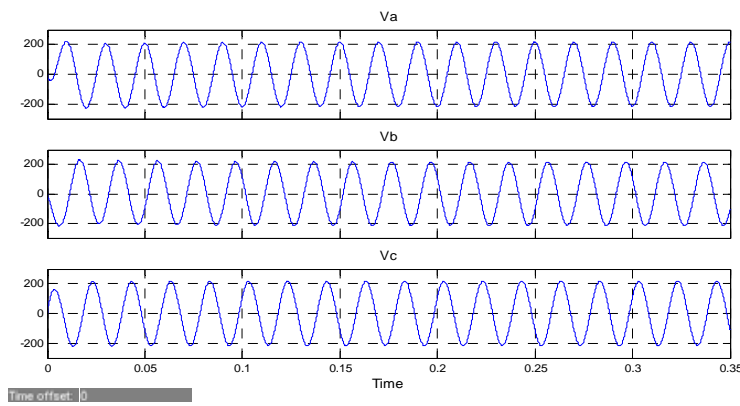

Figure 7. Three phase Voltage (RMS) values at MG side
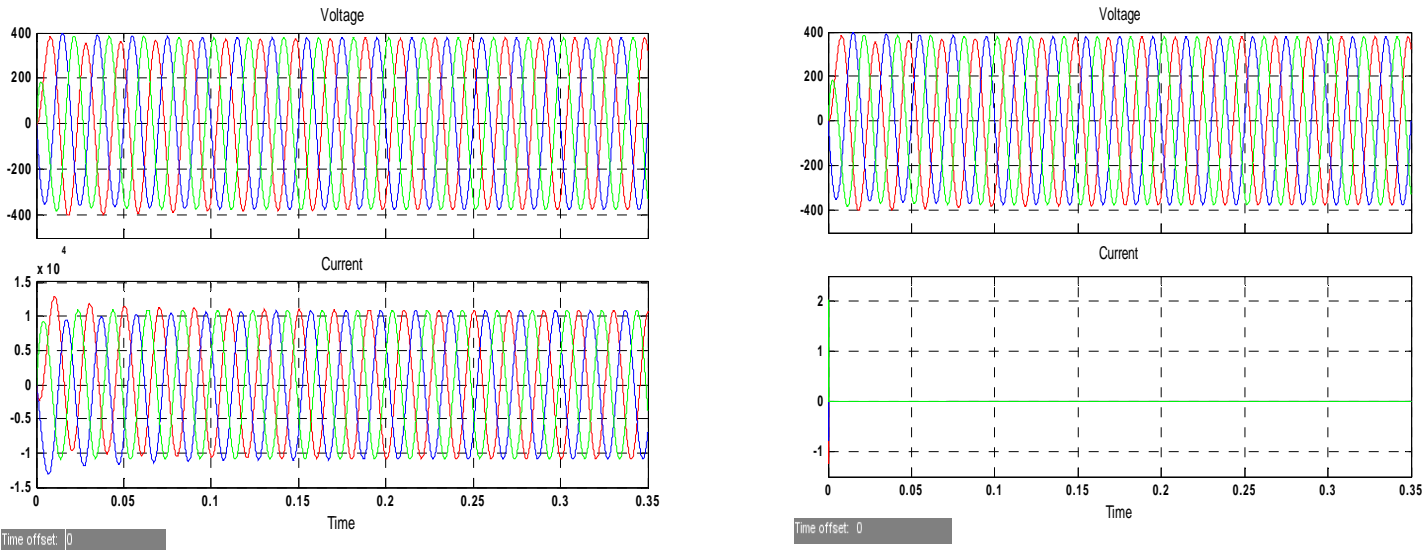

Figure 8. Voltage (top) and current (bottm) signals at critical load side (left) and at non-critical load side (right). Line voltage increased to $400 \mathrm{~V}$, but line current was zero at non-critical load side 
From the above simulation results, it is presented that, RE based microgrids can work as individual energy generation unit for small community. In addition, the simple control technique used in the simulations is able to manage energy supply to the loads according to generation and urgency.[35]

\section{CONCLUSION}

Microgrid has valuable potential to become the global energy solution. In this system, electricity generation is mainly done by utilizing RE sources that ensure clean environment as well. As the system becomes complex because of different miocrosources, suitable control system is required for flexibility and efficiency of the system. In this paper, simulation on the microgrid system that uses DER (PV) with and without controller employing critical and non-critical loads has been presented. The simulations results show that continuous power supply to the critical loads and disconnecting the non-critical loads when the voltage level in microgrid side is lower than the threshold level can be maintained effectively by the controller. Further study will focus on controlling MG at grid failure period (in grid connected mode) using all three DERs such as solar PV, wind turbine and fuel cell. A more advanced controller will be designed in this regard.

\section{ACKNOWLEDGEMENTS}

The authors wish to acknowledge the support from Ministry of Science, Technology and Innovation (MOSTI) Malaysia and Universiti Teknologi Malaysia UTM), for the award of the grant that has enabled the research, leading to this article under the E-Science grant (vote No: R.J130000.7923.4S068).

\section{REFERENCES}

[1] Chen, Y.K., et al., Design and implementation of energy management system with fuzzy control for DC microgrid systems. Power Electronics, IEEE Transactions on, 2013. 28(4): p. 1563-1570.

[2] Agency, U.S.E.P. Overview of Greenhouse Gases. 2015 [cited 201522 May]; Available from: http://www.epa.gov/climatechange/ghgemissions/gases.html.

[3] Zhang, L., N. Gari, and L.V. Hmurcik, Energy management in a microgrid with distributed energy resources. Energy Conversion and Management, 2014. 78: p. 297-305.

[4] Bagherian, A. and S.M.M. Tafreshi, A developed Energy Management System for a Microgrid in the Competitive Electricity Market. 2009 Ieee Bucharest Powertech, Vols 1-5, 2009: p. 1756-1761.

[5] Mahmoud, M., S.A. Hussain, and M. Abido, Modeling and control of microgrid: an overview. Journal of the Franklin Institute, 2014. 351(5): p. 2822-2859.

[6] Palizban, O. and K. Kauhaniemi, Hierarchical control structure in microgrids with distributed generation: Island and grid-connected mode. Renewable and Sustainable Energy Reviews, 2015. 44: p. 797-813.

[7] Arul, P., V.K. Ramachandaramurthy, and R. Rajkumar, Control strategies for a hybrid renewable energy system: A review. Renewable and Sustainable Energy Reviews, 2015. 42: p. 597-608.

[8] Chowdhury, S. and P. Crossley, Microgrids and active distribution networks. 2009: The Institution of Engineering and Technology.

[9] Minchala-Avila, L.I., et al., A review of optimal control techniques applied to the energy management and control of microgrids. Procedia Computer Science, 2015. 52: p. 780-787.

[10] Herbert, G.J., et al., A review of wind energy technologies. Renewable and sustainable energy Reviews, 2007. 11(6): p. 1117-1145.

[11] $\mathrm{Li}, \mathrm{H}$. and Z. Chen, Overview of different wind generator systems and their comparisons. IET Renewable Power Generation, 2008. 2(2): p. 123-138.

[12] Liu, X. and B. Su. Microgrids-an integration of renewable energy technologies. in Electricity Distribution, 2008. CICED 2008. China International Conference on. 2008. IEEE.

[13] Su, W. and J. Wang, Energy management systems in microgrid operations. The Electricity Journal, 2012. 25(8): p. 45-60.

[14] Energy, C.f.S. Microgrids. 2015 [cited 201523 may]; Available from: https://energycenter.org/self-generationincentive-program/business/technologies/microgrid.

[15] I-SMART, D.o.E.a.C.E., Realtime Simulation Platform.

[16] Siow, L., et al. Wi-Fi based server in microgrid energy management system. in TENCON 2009-2009 IEEE Region 10 Conference. 2009. IEEE.

[17] Hatziargyriou, N., et al., Microgrids. Power and Energy Magazine, IEEE, 2007. 5(4): p. 78-94.

[18] Chen, C., et al., Smart energy management system for optimal microgrid economic operation. IET renewable power generation, 2011. 5(3): p. 258-267.

[19] Sanseverino, E.R., et al., An execution, monitoring and replanning approach for optimal energy management in microgrids. Energy, 2011. 36(5): p. 3429-3436. 
[20] Kremers, E., J. Gonzalez de Durana, and O. Barambones, Multi-agent modeling for the simulation of a simple smart microgridPlease check and approve the edit made in the article title. Energy Conversion and Management, 2013. 75: p. 643-650.

[21] Pogaku, N., M. Prodanovic, and T.C. Green, Modeling, analysis and testing of autonomous operation of an inverter-based microgrid. Power Electronics, IEEE Transactions on, 2007. 22(2): p. 613-625.

[22] Vaccaro, A., et al., An integrated framework for smart microgrids modeling, monitoring, control, communication, and verification. Proceedings of the IEEE, 2011. 99(1): p. 119-132.

[23] Tsikalakis, A.G. and N.D. Hatziargyriou. Centralized control for optimizing microgrids operation. in Power and Energy Society General Meeting, 2011 IEEE. 2011. IEEE.

[24] Lasseter, R.H. Microgrids. in Power Engineering Society Winter Meeting, 2002. IEEE. 2002. IEEE.

[25] Bidram, A. and A. Davoudi, Hierarchical structure of microgrids control system. Smart Grid, IEEE Transactions on, 2012. 3(4): p. 1963-1976.

[26] Ahmed, O. and J. Bleijs, Power flow control Methods for an ultracapacitor bidirectional converter in DC microgrids—A comparative study. Renewable and Sustainable Energy Reviews, 2013. 26: p. 727-738.

[27] Zamora, R. and A.K. Srivastava, Controls for microgrids with storage: Review, challenges, and research needs. Renewable and Sustainable Energy Reviews, 2010. 14(7): p. 2009-2018.

[28] Lasseter, R., et al., The CERTS microgrid concept, white paper on integration of distributed energy resources. California Energy Commission, Office of Power Technologies-US Department of Energy, LBNL-50829, http://certs.lbl.gov, 2002.

[29] Hiskens, I.A. and E.M. Fleming. Control of inverter-connected sources in autonomous microgrids. in American Control Conference, 2008. 2008. IEEE.

[30] Hatziargyriou, N., A. Dimeas, and A. Tsikalakis, Centralized and decentralized control of microgrids. International Journal of Distributed Energy Resources, 2005. 1(3): p. 197-212.

[31] Peas Lopes, J., et al. Control strategies for microgrids emergency operation. in Future Power Systems, 2005 International Conference on. 2005. IEEE.

[32] Hatziargyriou, N., et al., Microgrids-large scale integration of microgeneration to low voltage grids. CIGRE C6309, 2006.

[33] Kaur, A., Modelling and Simulation of Central Controller to Control Power Sharing In Microgrid. 2014, THAPAR UNIVERSITY PATIALA.

[34] Selvi, M.T., A Power Quality Improvement for Microgrid Inverter Operated In Grid Connected and Grid Disconnected Modes. Bulletin of Electrical Engineering and Informatics, 2014. 3(2): p. 113-118.

[35] Sumaiya Rahman, H.A.R., Design of PV in Microgrid as Energy Source and Control Method Using MATLAB/SIMULINK. 2015, IICIST.

\section{BIOGRAPHIES OF AUTHORS}

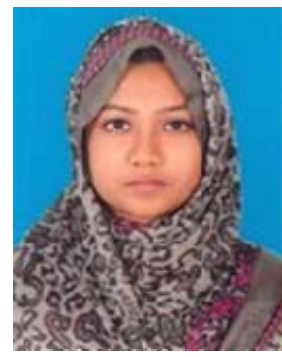

Sumaiya Rahmanis currently pursuing Master in Philosophy degree in the Centre of Electrical Energy Systems (CEES), Institute of Future Energy, Faculty of Electrical Engineering, Universiti Teknologi Malaysia (UTM). She received her B.Sc. degree in Electrical and Electronics Engineering from United International University, Dhaka, Bangladesh, in 2014. Her research interests include Microgrid Energy Management System, Smart Grid, and Renewable Energy etc.

Email address: sumaiya_r@yahoo.com

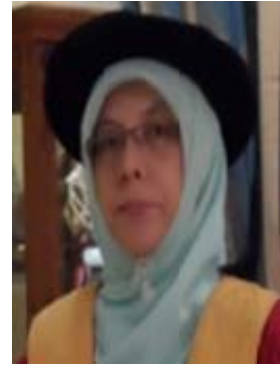

Dr Hasimah Abdul Rahman is an Associate Professor at Faculty of Electrical Engineering, Universiti Teknologi Malaysia (UTM). She obtained her B.Sc. in EEE from University of Aberdeen, UK in 1988, MSc in Energy Studies from University of Wales, College of Cardiff in 1995 and PhD in Electrical Engineering from UTM in 2012. She is the Deputy Director of Centre of Electrical Energy Systems (CEES), UTM. She has more than 20 years of experience in teaching electrical engineering courses and supervision of more than 60 undergraduates and 6 post graduates students and has authored and co-authored for more than 30 journal and conference papers. She was involved in the "National Energy Conservation Study" under the Ministry of Energy Telecom and Post, Malaysia (METP) in 1993. She has also served as an energy audit consultant on behalf of ISI, UTM for the industries and commercial buildings. She also involves Solar Decathlon China 2013 competition in designing UTM-Solar House. She is a member of Institute Electrical Electronic Engineer (MIEEE), Registered Graduate Engineer with the Board of Engineers Malaysia (BEM) and Graduate Member of Institution of Engineers Malaysia (IEM). She holds a Cert. Grid-PV (ISPQ-SEDA, Malaysia). Her research interest includes RE technology, energy efficiency, demand side management and its environmental impact. Her specialize area of research is on solar PV. 